\title{
Synoptic-Scale Air-Sea Flux Forcing in the Western North Pacific: Observations and Their Impact on SST and the Mixed Layer
}

\author{
Bo Qiu, Shuiming Chen, And Peter Hacker \\ Department of Oceanography, University of Hawaii at Manoa, Honolulu, Hawaii
}

(Manuscript received 17 December 2003, in final form 1 April 2004)

\begin{abstract}
Decade-long surface meteorological measurements from a Japan Meteorological Agency buoy at $29^{\circ} \mathrm{N}, 135^{\circ} \mathrm{E}$ are analyzed to elucidate the surface air-sea flux forcing in the western North Pacific Ocean. Besides the welldefined annual cycles, the observed heat and momentum fluxes are dominated by signals related to synopticscale weather disturbances. The synoptic-scale heat flux signals have a dominant time scale of 3-14 days, whereas the wind stress signals have a scale of 2-8 days. A comparison between the heat fluxes estimated using the buoy measurements and those from the NCEP reanalysis reveals that the daily NCEP product overestimates both the incoming solar radiation at sea surface and the turbulent heat flux amplitude associated with the individual weather events. The rms amplitude of the synoptic-scale net heat flux of the NCEP product is found to be positively biased by $23 \%$. Despite this amplitude bias, the NCEP product captures the timing and relative strength of the synoptic-scale net heat flux forcing very well. A favorable comparison is also found between the daily surface wind stress forcing from the buoy and that from the NCEP product on the synoptic time scales. Using a bulk surface mixed layer model, we find that the synoptic-scale forcing can significantly change the SSTs in spring-summer seasons. The synoptic-scale heat flux-induced SST anomalies have a typical amplitude of $\pm 1^{\circ} \mathrm{C}$, whereas the wind-induced SST anomalies depend on the accumulation of large-amplitude wind events. Excessive accumulation, which occurred, for example, in 1997, can result in unseasonally cold summertime SST anomalies. From both the observations and the model, the frequency spectra for the synoptic-scale SST signals show a clear $\omega^{-2}$ dependency. While this dependency is consistent with the "white" surface heat flux forcing in the frequency band of 1/100-1/16 days, short-term mixed layer depth changes induced by the synoptic-scale atmospheric forcing are argued to be important in determining the SST spectral shape in the higher-frequency band.
\end{abstract}

\section{Introduction}

With the cold, dry air of the Eurasian continent overriding the warm waters transported by the oceanic western boundary current from the Tropics, the midlatitude western North Pacific Ocean is where heat exchange across the air-sea interface is the largest in the Pacific Ocean (Talley 1984; Hsiung 1985). Offshore of Japan, for example, the wintertime December-February (DJF) mean heat loss from the ocean to atmosphere can reach a regional maximum as high as $350 \mathrm{~W} \mathrm{~m}^{-2}$ (Fig. 1a). Coupled with the intense surface wind forcing, this large heat loss contributes to the regional formation of the subtropical and central mode waters [see Hanawa and Talley (2001) for a comprehensive review]. Through lateral induction of the thermocline water across the spatially sloping mixed layer, the excessive heat loss region of the western North Pacific is also where subsurface temperature anomalies can be preferentially en-

Corresponding author address: Dr. Bo Qiu, Department of Oceanography, University of Hawaii at Manoa, 1000 Pope Road, Honolulu, HI 96822.

E-mail: bo@ soest.hawaii.edu trained to the surface mixed layer (Qiu and Huang 1995), providing a source for nonseasonal sea surface temperature (SST) anomalies.

While the climatology of the surface heat flux forcing, such as that presented in Fig. 1a, is well established, our understanding of the shorter-time-scale air-sea flux forcing remains more fragmentary. This deficiency in our understanding owes largely to the lack of in situ surface meteorological measurements over the open oceans. In the midlatitude eastern North Pacific, longterm surface meteorological measurements are limited to the Ocean Weather Stations Papa (OWS P; $50^{\circ} \mathrm{N}$, $145^{\circ} \mathrm{W}$ ) and November (OWS N; $\left.30^{\circ} \mathrm{N}, 140^{\circ} \mathrm{W}\right)$, and in the western North Pacific, they are limited to several Japan Meteorological Agency (JMA) buoys in the seas around Japan. The in situ measurements from the OWSs $\mathrm{P}$ and $\mathrm{N}$ have been used extensively in the past in testing and improving ocean mixed layer models (e.g., Martin 1985; Gasper 1988; Large 1996). In contrast, the in situ data from the JMA buoys in the western North Pacific have been utilized less frequently because of the complications of strong lateral current advection (Kurasawa et al. 1983; see Fig. 1b) and active mesoscale eddy activity. 

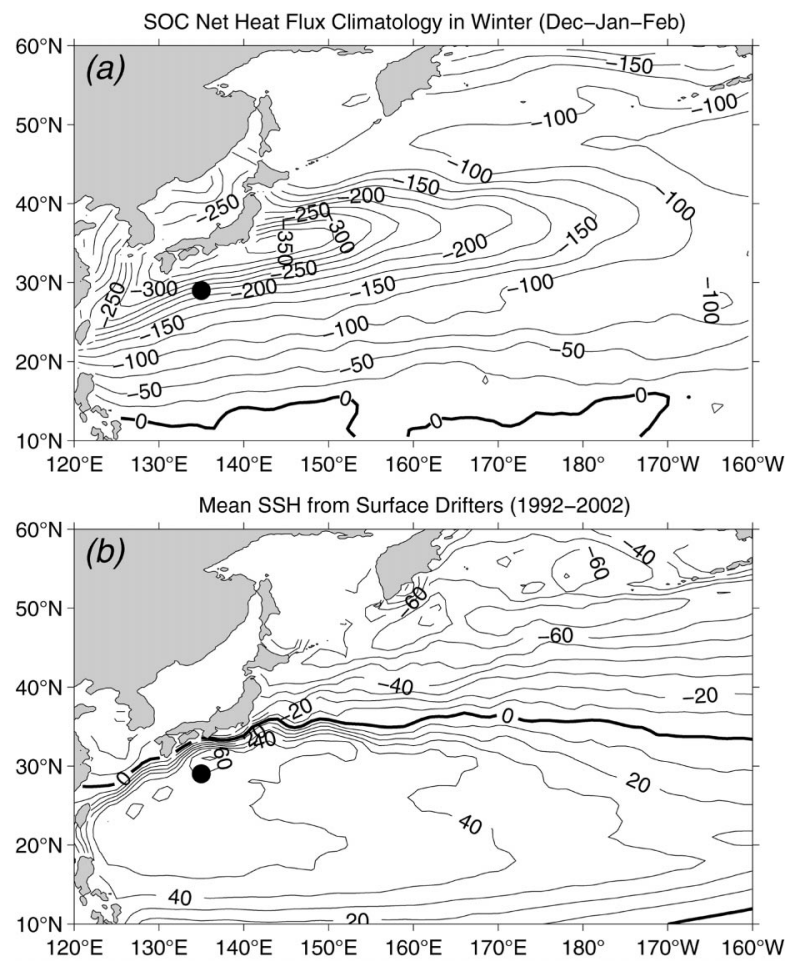

FIG. 1. (a) Wintertime (DJF) mean net heat flux $\left(\mathrm{W} \mathrm{m}^{-2}\right)$ over the western North Pacific Ocean from the SOC monthly climatology (Josey et al. 1998). Negative values indicate heat loss from the ocean to the atmosphere. The dot at $29^{\circ} \mathrm{N}, 135^{\circ} \mathrm{E}$ denotes the location of the JMA buoy 21004. (b) Mean sea surface height $(\mathrm{cm})$ derived from surface drifters in 1992-2002 (Niiler et al. 2003).

In recent years, many data analysis studies have highlighted the interannual-to-decadal SST changes in the western North Pacific (e.g., Miller et al. 1994; Deser and Blackmon 1995; Nakamura et al. 1997). Numerical modeling studies by Latif and Barnett (1996), Peng et al. (1997), and Barnett et al. (1999) have further shown that these SST anomalies can influence the overlying atmospheric circulation by changing the baroclinicity and positions of midlatitude storms, leading to an enhancement in the decadal variability of the midlatitude North Pacific climate system. Given its importance to the oceanic ventilation processes and the SST signals, a careful examination of the air-sea flux forcing in the western North Pacific is clearly called for.

The objective of this study is to first document and evaluate the long-term, air-sea flux time series using the in situ measurement data from the JMA buoy 21004. As shown in Fig. 1, the buoy was located at $29^{\circ} \mathrm{N}, 135^{\circ} \mathrm{E}$ and was known formerly as OWS T (e.g., Kurasawa et al. 1983). Situated in the Kuroshio recirculation south of Japan, buoy 21004 is close to the center of the maximum wintertime heat loss from the ocean to the atmosphere. Our analyses focus on the 1990s because this is the decade in which high-quality, continuous measurements were obtained by the buoy (JMA 2001).

In the past, gridded surface heat flux products from operational weather forecast assimilation and analysis models have been used in studies investigating the western North Pacific SST variability (e.g., Qiu 2000; Vivier et al. 2002; Kelly 2004). The long-term JMA buoy observations provides us with a unique reference dataset to compare in situ measurements with those from the operational models. For comparisons in this study, we use the daily reanalysis product from the National Centers for Environmental Prediction (NCEP; Kistler et al. 2001).

The second objective of this study is to investigate how the observed surface flux forcing, especially that at the submonthly time scale, can affect the surface ocean thermal structure. Reflecting the midlatitude synoptic-scale weather disturbances, submonthly high-frequency forcing prevails in the western North Pacific throughout the year. To fully understand the effect of this forcing would involve clarifying dynamically and thermodynamically coupled processes in a three-dimensional setting. This, unfortunately, is beyond the scope of the present study. In this paper, we instead focus only on the thermodynamic effect of the synoptic-scale heat flux and wind forcing. Specifically, by adopting the mixed layer model of Price et al. (1986, hereafter PWP), we examine how the observed high-frequency forcing can impact upon the mixed layer depth and sea surface temperature signals.

Following a brief description of the JMA buoy measurements in the next section, we discuss the observed surface heat and momentum fluxes evaluated from the bulk formulas. Section 3 provides comparisons between the buoy-derived surface heat and momentum flux time series and the surface flux product from the NCEP reanalysis. In section 4, we explore the impact of the synoptic-scale surface forcing upon the upper-ocean thermal structures. Results of this study are discussed and summarized in section 5 .

\section{JMA buoy measurements}

Operational buoys have been deployed by JMA in the seas around Japan for meteorological and oceanographic observations in the past decades. Buoy 21004 (Fig. 1) was equipped to measure air temperature, wetbulb temperature, solar radiation, air pressure, and wind speed/direction. Below the air-sea interface, water temperatures near the surface and at the depths of 50 and $100 \mathrm{~m}$ were also measured. Sampling interval was nominally $3 \mathrm{~h}$ and increased to hourly when the wind speed exceeded $35 \mathrm{kt}\left(\sim 18 \mathrm{~m} \mathrm{~s}^{-1}\right)$.

To determine the turbulent (i.e., sensible + latent) heat fluxes from the in situ buoy measurements, we adopt in this study the Coupled Ocean-Atmosphere Response Experiment (COARE) flux algorithm developed by Fairall et al. (1996). In addition to the Tropical Ocean Global Atmosphere (TOGA) COARE program, the bulk formulas of Fairall et al. have in the past been used to evaluate the turbulent heat fluxes for the Subduction 
Experiment in the midlatitude North Atlantic (Moyer and Weller 1997; Josey 2001) and for the Arabian Sea Experiment in the Indian Ocean (Weller et al. 1998). In applying the Fairall et al. (1996) algorithm, we first calculate relative humidity from the air temperature, wet-bulb temperature, and air pressure data. Sensible and latent heat fluxes are then computed with the input of the observed wind speed, air temperature, relative humidity, air pressure, and SST values to the algorithm. The daily mean values are finally formed by averaging the 3-hourly estimates.

To obtain the net shortwave radiation at the sea surface $\left(Q_{\text {sw }}\right)$, we use the observed solar radiation multiplied by $(1-\alpha)$, where $\alpha$ is the surface albedo. For the value of $\alpha$, which is a function of the atmospheric transmittance and solar altitude, we follow Payne's (1972) Table 1, with the atmospheric transmittance calculated as the ratio of the measured solar radiation to the insolation at the top of the atmosphere.

To obtain the net longwave radiation $\left(Q_{1 \mathrm{w}}\right)$, we use the following bulk formula (see Berliand and Berliand 1952; Fung et al. 1984):

$$
\begin{aligned}
Q_{\mathrm{lw}}= & -\epsilon \sigma T_{s}^{4}\left(0.39-0.05 \sqrt{e_{s}}\right)\left(1-0.64 C^{2}\right) \\
& -4 \epsilon \sigma T_{a}^{3}\left(T_{s}-T_{a}\right),
\end{aligned}
$$

where $\epsilon$ is the longwave emissivity at the ocean surface $(0.98), \sigma$ is the Stefan-Boltzmann constant $\left(5.67 \times 10^{-8}\right.$

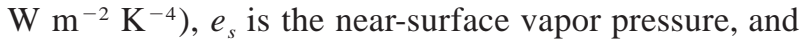
$T_{a}$ and $T_{s}$ are the air and surface water temperatures, respectively, in kelvins. In Eq. (1), the term (1 $0.64 C^{2}$ ) represents the cloud correction, with $C$ denoting the fractional cloud cover (Clark et al. 1974). Because $C$ is not a directly measured quantity, we follow Reed's (1977) formulation and estimate its value inversely from the measured solar radiation $\left(Q_{\mathrm{sol}}\right)$ and the clear-sky insolation $\left(Q_{\mathrm{cls}}\right)$ :

$$
Q_{\text {sol }}=Q_{\text {cls }}(1-0.62 C-0.0019 A),
$$

where $A$ is the noon solar altitude in degrees. Like the turbulent heat flux data, the daily mean radiative heat flux (i.e., $Q_{\mathrm{sw}}+Q_{\mathrm{lw}}$ ) values are formed by averaging the 3-hourly estimates.

To calculate the surface momentum fluxes, we use the bulk formula: $\boldsymbol{\tau}=\rho_{a} C_{d}\left|\mathbf{u}_{10}\right| \mathbf{u}_{10}$, where $\rho_{a}$ is the air density and $\mathbf{u}_{10}$ is the wind velocity at $10-\mathrm{m}$ height. For the drag coefficient, $C_{d}$, the following empirical formula presented by Large (1996) is adopted:

$$
C_{d}=\left(\frac{2.70}{\left|\mathbf{u}_{10}\right|}+0.142+0.0764\left|\mathbf{u}_{10}\right|\right) 10^{-3} .
$$

Figure 2 shows the time series of the daily turbulent and radiative heat fluxes calculated from the bulk formulas described above. Both time series have well-defined annual cycles: heat gain of the ocean through radiative flux has a maximum in July, whereas the heat loss due to the turbulent fluxes has a maximum in Jan-
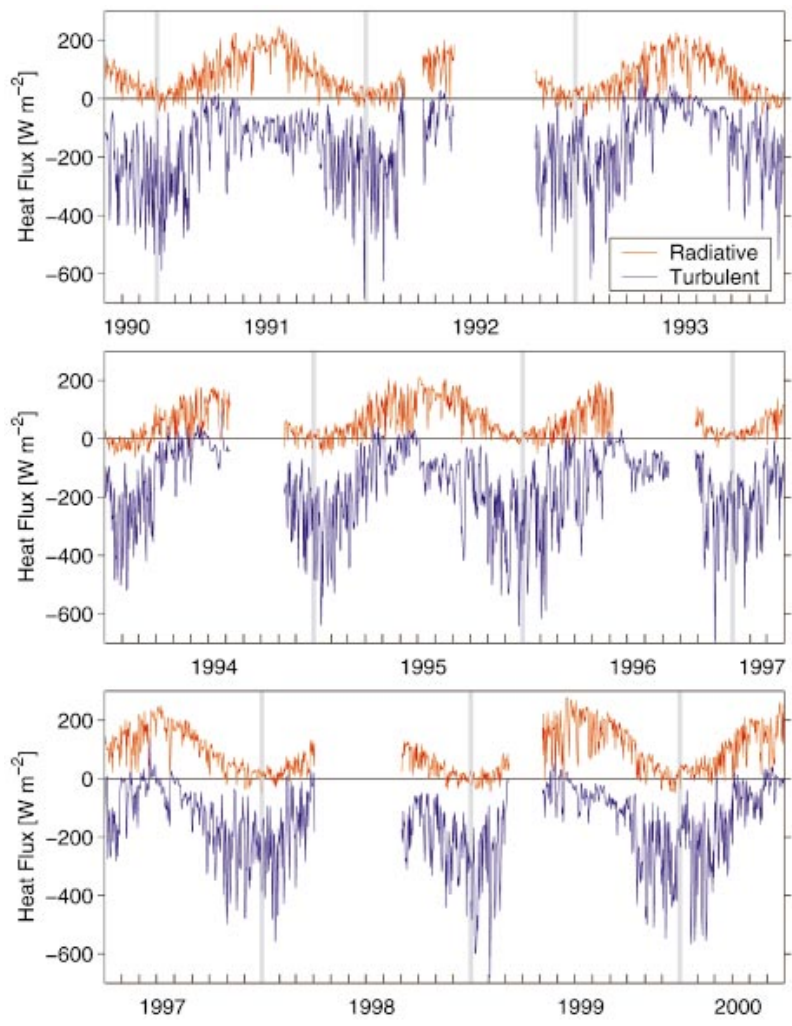

FIG. 2. Time series of the daily radiative (net shortwave + net longwave) and turbulent (latent + sensible) heat fluxes measured by the JMA buoy 21004.

uary. Superimposed on these seasonal variations are the high-frequency perturbations resulting from synopticscale weather systems. Influence of these transient weather systems are particularly strong in the fall and winter seasons when the storm-induced turbulent heat flux variations can reach as high as $400 \mathrm{~W} \mathrm{~m}^{-2}$. Impact of the transient weather systems can also been seen in the radiative heat flux time series, although at reduced amplitudes. A spectral analysis of the heat flux time series (Fig. 3a) reveals that the high-frequency heat flux perturbations do not have a distinct spectral peak. Rather, large-amplitude perturbations appear in a relatively broad frequency band of $1 / 14-1 / 3$ days.

Figure 4 shows the time series of the daily zonal and meridional wind stresses from the buoy observations. Located in the transition zone between the westerlies and the trade winds (e.g., Trenberth et al. 1990), the mean surface wind stress at the buoy site is close to zero. Similar to the surface heat flux time series, synoptic-scale weather systems again dominate the surface wind stress signals. In particular, passages of typhoons are responsible for the episodic, large-amplitude wind events (i.e., $|\tau|>0.5 \mathrm{~N} \mathrm{~m}^{-2}$ ) seen in summer and autumn. Persistent northwesterly wind fluctuations seen in winter, on the other hand, reflect the prevalence of winter storms in the region. As compared with the surface heat flux forcing, the spectral analysis indicates that 

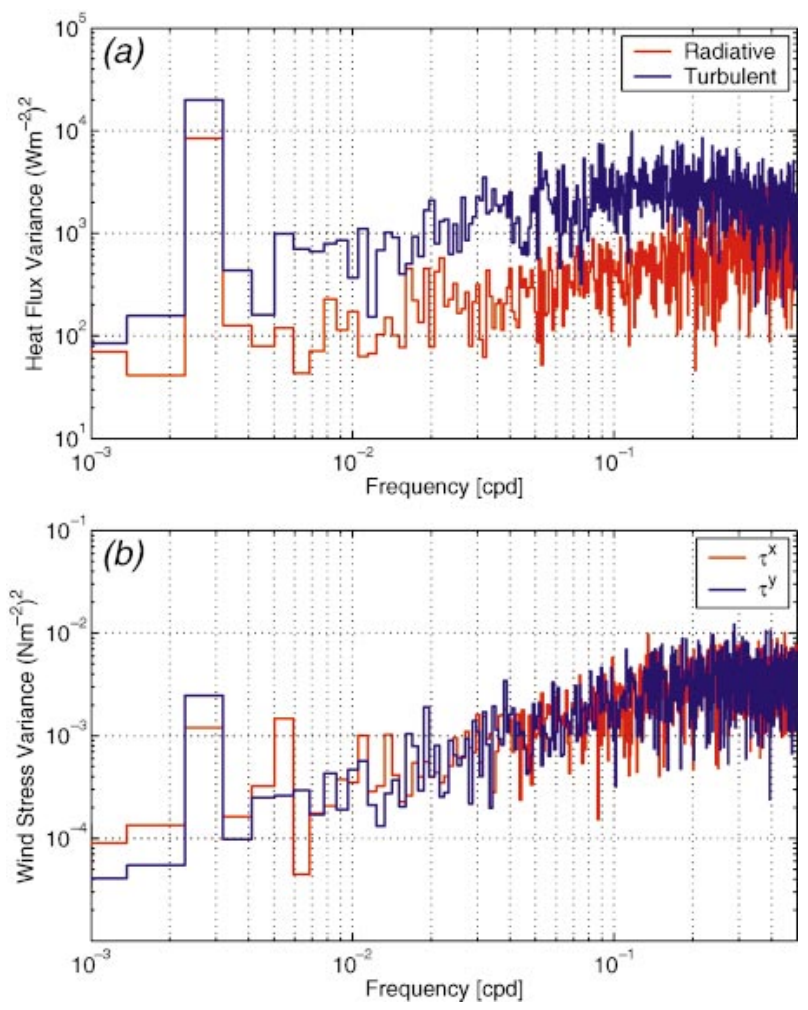

FIG. 3. Frequency spectra for (a) the radiative and turbulent heat fluxes and (b) the zonal and meridional wind stresses. The heat flux and wind stress time series are presented in Figs. 2 and 4, respectively. The spectra are shown in variance-preserving format.

the surface wind stress forcing has a weaker annual cycle and that the high-frequency signals have more energy in the higher frequency band of $1 / 8-1 / 2$ days (see Fig. 3b). The reason for this latter difference is in part due to the fact that the turbulent heat fluxes are related linearly to the surface wind signals, whereas the wind stresses are proportional to the square of the surface wind signals.

\section{Air-sea flux comparisons}

Given their global coverage and temporal continuity, air-sea flux products from operational forecast models have been widely used as the surface boundary conditions for ocean modeling studies. In this section, we compare the daily heat and momentum fluxes determined from the buoy measurements with those from the NCEP reanalysis (Kistler et al. 2001).

\section{a. Annual cycles of surface heat fluxes}

Figure 5 compares the monthly mean turbulent and radiative heat fluxes from the buoy data and the NCEP product $^{1}$ for the period from October 1990 to June 2000.

\footnotetext{
${ }^{1}$ The NCEP time series is derived by bilinear interpolation from the daily NCEP reanalysis product available on the $1.904^{\circ}$ lat $\times$ $1.875^{\circ}$ lon Gaussian grid.
}
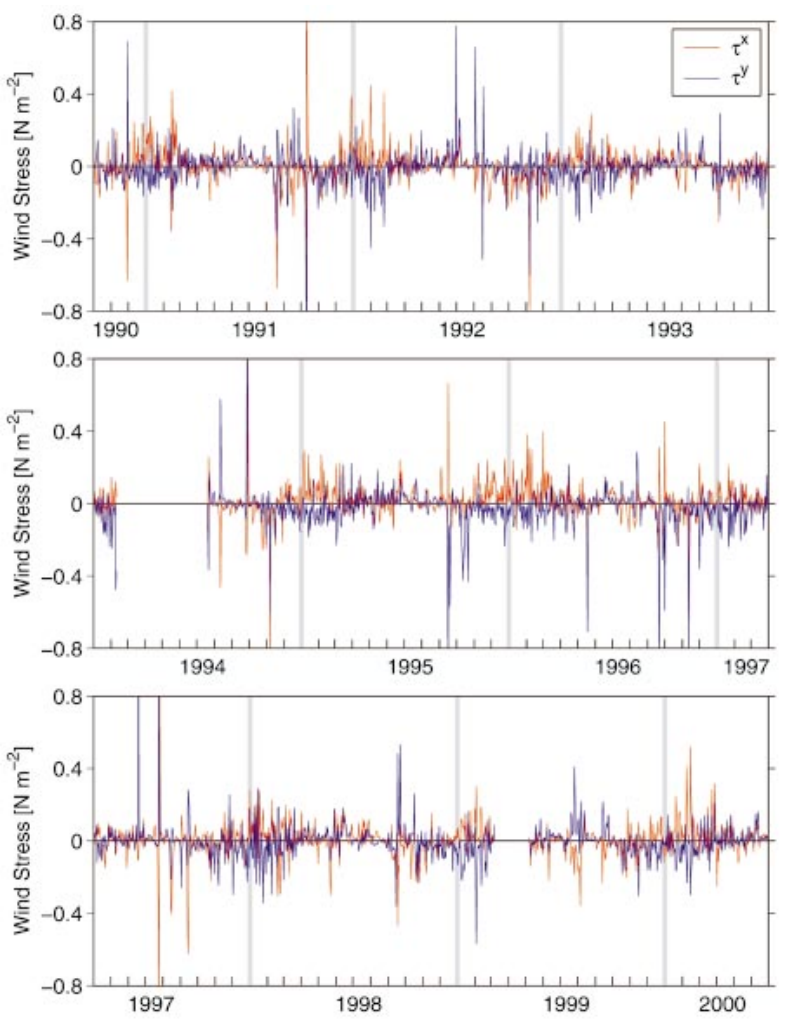

FIG. 4. Time series of the daily surface wind stresses measured by the JMA buoy 21004.

For the turbulent heat fluxes, the buoy estimate has a seasonally varying amplitude smaller than that of the NCEP product. The discrepancy between the two estimates is particularly large $\left(\sim 80 \mathrm{~W} \mathrm{~m}^{-2}\right)$ during the winter season. As will become clear in the following subsection, this discrepancy is attributable to the fact that the NCEP product persistently overestimates the magnitude of the wintertime storm-induced heat loss from the ocean to the atmosphere. Similar bias has been identified in previous studies that compared the NCEP turbulent heat fluxes with available in situ measurements in other areas of the world's oceans (e.g., Moyer and Weller 1997; Smith et al. 2001; Josey 2001).

For the radiative heat fluxes, Fig. 5b shows that the buoy estimate has its monthly mean values also smaller than the NCEP product. Because the radiative and turbulent heat fluxes contribute oppositely to the net surface heat flux $\left(Q_{\text {net }}\right)$, the discrepancy between the buoy and NCEP in terms of $Q_{\text {net }}$ is somewhat smaller: the rms difference between the monthly buoy and NCEP $Q_{\text {net }}$ values is $33.4 \mathrm{~W} \mathrm{~m}^{-2}$. Averaged annually, the net surface heat flux at the buoy site is $-58.8 \mathrm{~W} \mathrm{~m}^{-2}$ from the buoy measurements, while that of the NCEP product is $-75.7 \mathrm{~W} \mathrm{~m}^{-2}$.

Surface heat flux climatologies over the world's oceans have been compiled by several previous studies. To put the buoy result in the context of climatology, we 
(a) Turbulent Heat Flux Climatology

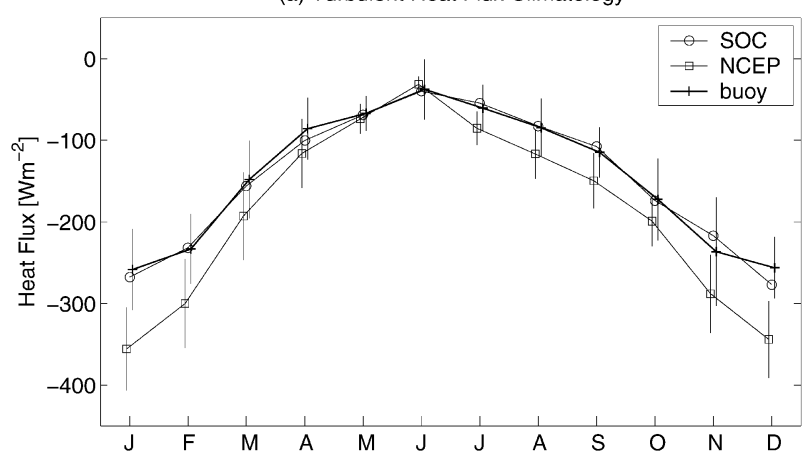

(b) Radiative Heat Flux Climatology

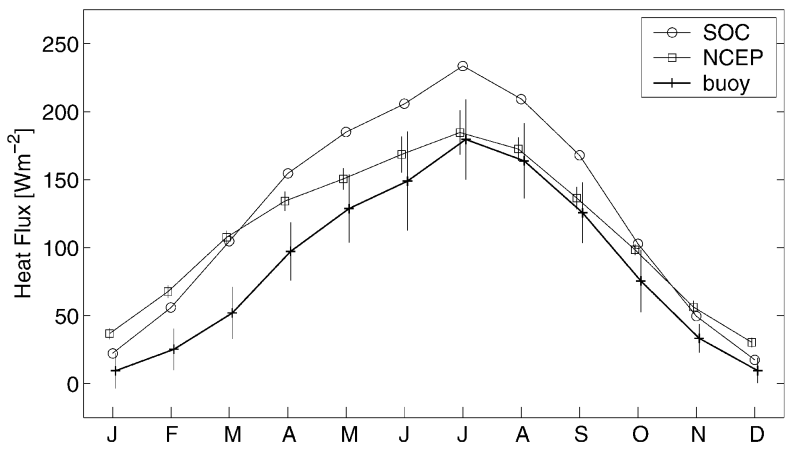

FIG. 5. Comparisons of (a) the monthly turbulent heat flux and (b) the monthly radiative heat flux climatologies from the JMA buoy 21004 observations, the SOC climatology, and the NCEP reanalysis product. Vertical bars associated with the buoy and the NCEP time series indicate their respective one standard deviations.

have also included in Fig. 5 the monthly turbulent and radiative heat flux values from the Southampton Oceanography Centre (SOC) climatology (Josey et al. 1998). Figure 5a shows that the monthly, buoy-based turbulent heat flux values agree exceptionally well with those of the SOC climatology. However, a persistent bias exists between the buoy and SOC's radiative heat fluxes (Fig. $5 b)$. This bias is largest during the spring and summer seasons wherein the SOC climatology exceeds the buoy estimate by $\sim 40 \mathrm{~W} \mathrm{~m}^{-2}$. A check into the flux components indicates that much of this bias stems from the difference in the estimated net shortwave radiation $\left(Q_{\mathrm{sw}}\right)$ values. Notice that while the surface solar radiation is a directly measured quantity by the JMA buoy, the $Q_{\text {sw }}$ climatology of SOC used Reed's (1977) empirical formulation based on clear-sky solar radiation and the estimated monthly mean fractional cloud cover [i.e., Eq. (2)].

By comparing concurrent measurements of the incoming solar radiation and the cloud cover at JMA observatories around Japan, a recent study by Kizu (1998) found that Reed's (1977) formulation consistently overestimates the incoming solar radiation at the sea surface. The overestimation was identified by Kizu to be particularly severe under overcast conditions, which prevail in spring and summer seasons in the regions surrounding

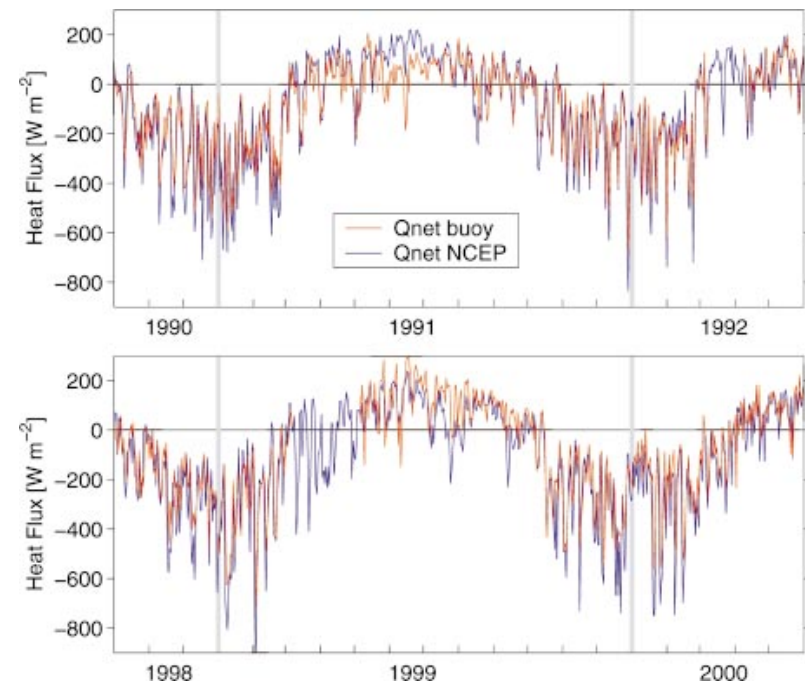

FIG. 6. Comparisons between the daily net heat flux time series from the buoy 21004 measurements (red) and from the NCEP reanalysis (blue). The buoy time series is the sum of the turbulent and radiative heat fluxes presented in Fig. 2. For brevity, the comparisons are shown for the two 1.75 -yr segments only; the results are typical for the rest buoy time series.

Japan. Our comparison shown in Fig. 5b is consistent with the findings by Kizu (1998), suggesting that care is needed in using the SOC's radiative heat flux climatology in cloudy regions, such as the western North Pacific.

\section{b. Synoptic-scale net heat fluxes}

For a visual comparison between the high-frequency net surface heat flux signals, we superimpose in Fig. 6 the $Q_{\text {net }}$ time series from the buoy and the NCEP product. Notice that for brevity, only two segments (which are representative of the remaining time series of the 1990s) are shown. Overall, the two time series compare quite favorably, with the NCEP time series capturing most of the storm-related, large-amplitude fluctuations during the fall and winter seasons. In the summer season, although some of the differences appear more apparent, the timing of individual perturbations seems again to match quite well.

For a more quantitative comparison between the $Q_{\text {net }}$ time series from the buoy and NCEP, we calculate their coherency $(\gamma)$ and phase lag using the concurrent $Q_{\text {net }}$ data available in the period from October 1990 to June 2000 (see Fig. 7). Here, $\gamma$ is defined as $S_{x y}(\omega) /$ $\left[S_{x x}(\omega) S_{y y}(\omega)\right]^{1 / 2}$, where $\omega$ is frequency, $S_{x x}(\omega)$ and $S_{y y}(\omega)$ are the autospectral density functions of the buoy and NCEP $Q_{\text {net }}$, and $S_{x y}(\omega)$ is their cross-spectral density function. As can be anticipated from Fig. 6, the coherency between the buoy and NCEP time series is high $(\gamma>0.5)$ and there exists no appreciable phase difference between the two signals with frequencies lower than $1 / 3$ days. For signals with higher frequencies, the 

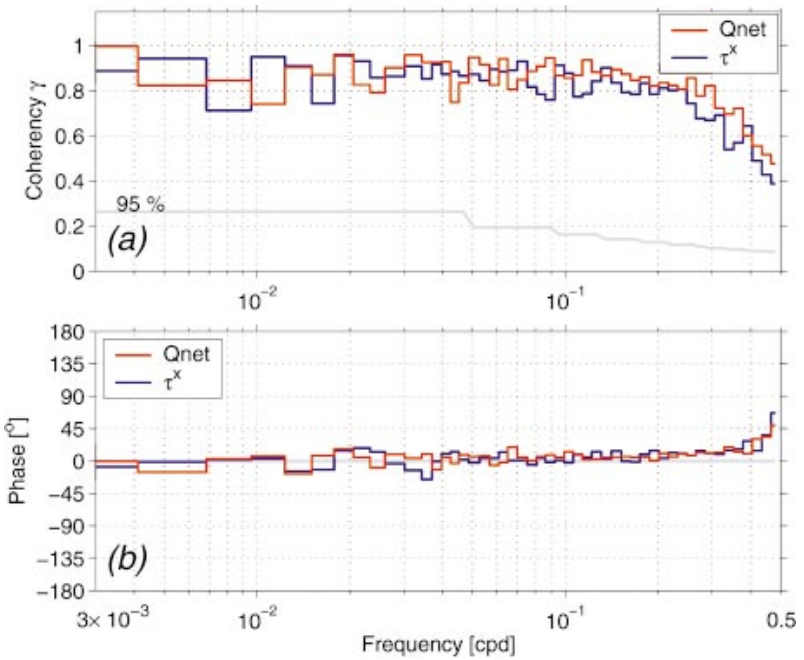

FIG. 7. (a) Coherency $\gamma$ and (b) phase lag between the daily time series of the net heat flux (red) and the zonal wind stress (blue) from the buoy 21004 measurements and the NCEP reanalysis. In (b), a positive phase lag indicates the lead of the buoy data over the NCEP product.

coherency becomes lower and there appears a tendency for the NCEP signals to lag those observed by the buoy.

Notice that although the timing of individual events matches well, a close look at Fig. 6 reveals that the NCEP product tends to overestimate the amplitude of the heat loss from the ocean to atmosphere. Accumulation of this overestimation results in the bias with the NCEP monthly mean turbulent heat flux values being larger than those estimated from the buoy as we found in Fig. 5a. To quantify this bias in the synoptic-scale net heat flux forcing of the NCEP product, we highpass filtered the $Q_{\text {net }}$ time series from the buoy and NCEP with a cutoff period at 2 months. The ratio between the rms values of the resultant time series (NCEP/ buoy) is 1.23 (see Table 1), indicating that the synopticscale $Q_{\text {net }}$ values in the NCEP product are biased high by about $23 \%$.

\section{c. Synoptic-scale surface wind stresses}

Figure 8 provides a visual comparison between the high-frequency wind stress signals from the buoy and NCEP. Similar to the high-frequency net heat flux signals, most of the large-amplitude wind events detected by the buoy are captured well in the NCEP time series. Analyses of the coherency and phase between the two decade-long time series of the wind stresses from the buoy and NCEP reveal a result similar to that found for the $Q_{\text {net }}$ time series. Specifically, all signals with period longer than 3 days are highly correlated and have little phase lags (see the blue lines in Fig. 7).

Unlike the synoptic-scale $Q_{\text {net }}$ signals, however, Fig. 8 shows that there appear no consistent overestimations of wind stresses for the individual high-wind events in
TABLE 1. Ratios of the rms variability in the NCEP reanalysis flux data to that from the JMA buoy observations. For both the neat heat flux $\left(\mathrm{Q}_{\text {net }}\right)$ and wind stress $\left(\tau^{x}, \tau^{y}\right)$ data, the rms values are calculated from the daily high-pass-filtered (with a cutoff period at 2 months) time series. For ratios of the wind stresses, the values in the parentheses denote those obtained when high-wind events (wind stress values $>0.7 \mathrm{~N} \mathrm{~m}^{-2}$ ) are excluded in calculating the rms values.

\begin{tabular}{cc}
\hline \hline Flux & Ratio \\
\hline$Q_{\text {net }}$ & 1.23 \\
$\tau^{x}$ & $0.86(1.00)$ \\
$\tau^{y}$ & $0.83(0.96)$ \\
\hline
\end{tabular}

the NCEP product. Some of very large amplitude wind events detected by the buoy (e.g., those in late August and in early October 1991) are, in fact, underestimated in the NCEP product. A simple comparison between the decade-long high-pass-filtered time series reveals that the ratios between the rms $\tau^{x}$ and $\tau^{y}$ variability of the NCEP product over those of the buoy estimate are 0.86 and 0.83 , respectively (Table 1$)$. It is important to emphasize that this underestimation by the NCEP product is mostly due to the high wind events related to regional typhoons. If we restrict our comparisons to the wind stress values smaller than $0.7 \mathrm{~N} \mathrm{~m}^{-2}$ (as presented in Fig. 4; this excludes seven large-amplitude events for $\tau^{x}$ and 9 for $\tau^{y}$ ), the ratio between the rms variability from the NCEP and the buoy becomes close to unity (see Table 1; ratios in parentheses). In summary, while underestimating episodic severe wind events, the daily NCEP wind stress product provides in general a reliable data set for the synoptic-scale surface momentum fluxes.
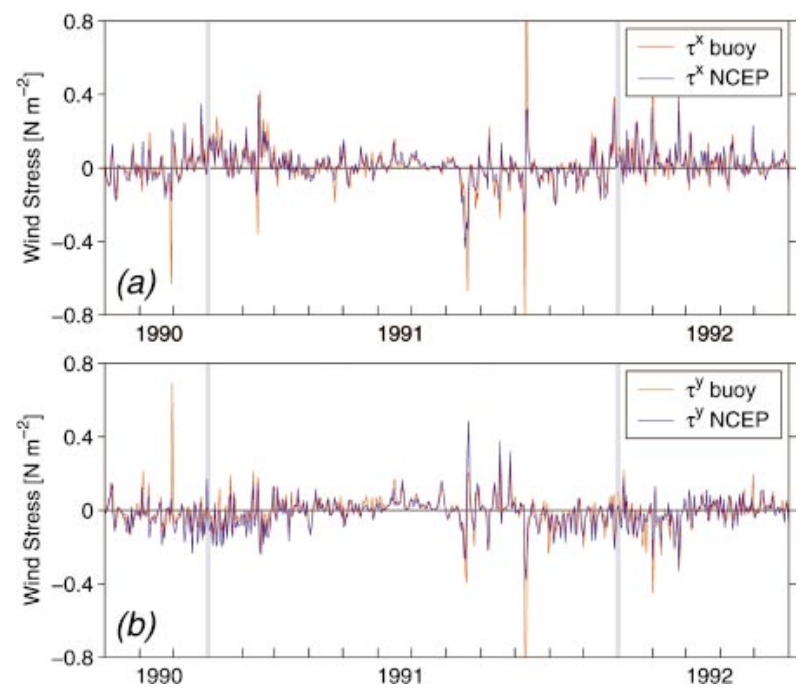

FIG. 8. Comparisons between (a) the daily zonal wind stress time series and (b) the daily meridional wind stress time series from the buoy 21004 measurements (red) and from the NCEP reanalysis (blue). For brevity, the comparisons are shown for a 1.75-yr segment only; the results are typical for the rest of the buoy time series. 


\section{Impact of the synoptic-scale air-sea flux forcing}

Given the vigorous synoptic-scale surface flux forcing observed at the buoy site, we attempt in this section to examine its impact upon the evolution of the surface ocean temperature and mixed layer structures. Because the annually averaged net surface heat flux at the buoy site is negative $\left(-58.8 \mathrm{~W} \mathrm{~m}^{-2}\right)$, it implies that lateral heat advection by the ocean circulation must play a role in order to maintain the thermodynamic equilibrium of the surface ocean. While this three-dimensional aspect of the mixed layer dynamics is important, we limit our investigation in this study to how the synoptic-scale surface flux forcing affects the development of the mixed layer in the vertical dimension. We believe this one-dimensional study provides a useful first step that will guide future studies dealing with the more complex three-dimensional effects.

\section{a. One-dimensional mixed layer model}

Our modeling study uses the one-dimensional bulk mixed layer model of Price et al. (1986). The skill of this model in reproducing observed mixed layer structures in the tropical and midlatitude oceans has been demonstrated by several previous studies (e.g., Schudlich and Price 1992; Large and Crawford 1995; Plueddemann et al. 1995; Anderson et al. 1996). In the PWP model, the surface mixed layer has constant temperature and velocity, and the wind stress is absorbed evenly within the "slab" mixed layer. Deepening of the mixed layer occurs when the surface ocean is gravitationally unstable or when the bulk Richardson number at the base of the mixed layer is below the critical value 0.65 . Vertical mixing in the water column also takes place whenever the local gradient Richardson number falls below the critical value 0.25 .

The model occupies the surface 400-m water column and has a vertical resolution of $1 \mathrm{~m}$. Following Paulson and Simpson (1977), surface heating due to shortwave radiation is absorbed in the water column with a double exponential depth dependence:

$$
q(z)=Q_{\mathrm{sw}}\left[R \exp \left(z / \gamma_{1}\right)+(1-R) \exp \left(z / \gamma_{2}\right)\right],
$$

where $R=0.6$ is a separation constant, and $\gamma_{1}=0.6$ $\mathrm{m}$ and $\gamma_{2}=20 \mathrm{~m}$ are the attenuation length scales. Because of lack of diurnal forcing, surface wind wave breaking, and Langmuir circulation, the model tends to trap the heat in a thin surface layer during summer when the wind forcing weakens and the heat flux forcing is dominated by heating. To alleviate this problem, we add a vertical eddy diffusion term $\partial_{z}\left[\kappa(z) \partial_{z} T\right]$ to the PWP dynamics, where $\kappa(z)=\kappa_{o} \exp \left(z / z_{o}\right)$, and the values $\kappa_{o}$ $=1.0 \times 10^{-4} \mathrm{~m}^{2} \mathrm{~s}^{-1}$ and $z_{o}=100 \mathrm{~m}$ are used. Notice that this added eddy diffusion term is only effective in the near-surface layer in summer; it has little impact upon the temperature evolution during the autumn/winter seasons when convective cooling and excessive wind stirring make the surface ocean well mixed. The model is initialized with the mean temperature profile at the JMA buoy site from the World Ocean Atlas 2001 (WOA01; Conkright et al. 2002). Because the regional surface thermal forcing is much greater than the freshwater flux forcing (see Fig. 2 in Qiu 2002), salinity and rainfall effects are not considered in this study.

To evaluate the impact of the high-frequency forcing, we conduct two model runs. In the "climatological" run case, the surface wind stress and heat flux forcing are given by their climatological monthly mean values observed at the buoy. To avoid drift of the mean state due to the neglect of horizontal advection, we offset the heat flux time series by its annual mean value of -58.8

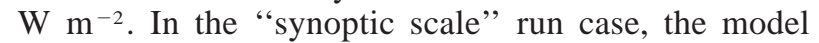
ocean is driven by the climatological monthly mean values (with the offset of $-58.8 \mathrm{~W} \mathrm{~m}^{-2}$ ) plus the observed high-frequency signals. ${ }^{2}$ Both models are run for a 10-yr period from July 1990 to June 2000. Effects of the high-frequency forcing are assessed by examining the differences between the two model runs.

\section{b. Model results}

Figure 9a shows the seasonal evolution of the upperocean temperature and mixed layer structures from the climatological run. Overall, the modeled signals bear a favorable resemblance to the observed upper-ocean structures (Fig. 9c). The observed signals are vertically more diffused, and this is likely due to the influences from interannual variability and lateral eddy fluxes that are not included in our PWP model runs. One noticeable difference between Figs. 9a and 9c is during summer when the modeled near-surface temperature is about $1^{\circ}-$ $2^{\circ} \mathrm{C}$ warmer than the observations. This warm bias is in part caused by the offset of the annual mean heat loss in the surface heat flux time series, which increases the surface heat input from the atmosphere. Another reason for the warm bias in the surface layer of the climatological run is that the modeled summertime mixed layer depth is too shallow, trapping the incoming radiative heat flux to a thin surface layer. Figure $9 b$ reveals that including the high-frequency air-sea flux forcing deepens the summertime mixed layer and cools the SST, in better agreement with the observations.

In Fig. 10, we plot the time series of the SST difference between the synoptic-scale and climatological model runs. Large-amplitude fluctuations can be seen each year from April to October when the mixed layer is relatively shallow. The cumulative effect of the synoptic-scale forcing works to lower the summertime

\footnotetext{
${ }^{2}$ The high-frequency signals are obtained by high-pass filtering the buoy heat flux and wind stress time series (Figs. 2 and 4) with a cutoff period at 2 months. For the periods when the buoy data are missing, we use the daily NCEP data. Following the analyses of section 3, the magnitude for the NCEP heat flux data is reduced by $23 \%$. No adjustment is made to the NCEP wind stress data.
} 

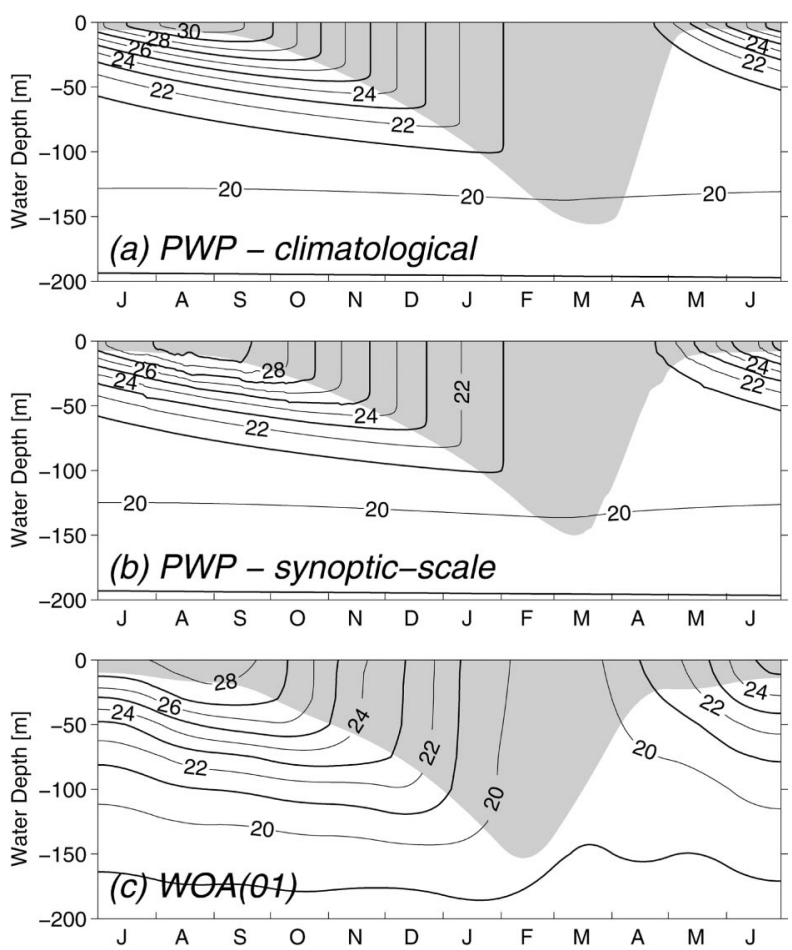

FIG. 9. Seasonal evolution of the upper-ocean temperature and mixed layer depth from (a) the climatological PWP model run, (b) the synoptic-scale model run, and (c) the WOA01 climatology. Both (a) and (b) are based on $10 \mathrm{yr}$ of the model outputs. The mixed layer depth for the WOA01 climatology is defined as where the water density is $0.125 \mathrm{~kg} \mathrm{~m}^{-3}$ greater than the surface water density.

SSTs. While this result is not unexpected given that the synoptic-scale forcing can enhance entrainment of the cold subsurface water into the surface mixed layer, the question regarding the relative importance of the synoptic-scale heat flux versus wind stress forcing remains to be addressed. Indeed, Fig. 10 reveals that the magnitude of synoptic-scale forcing-induced summertime surface cooling varies significantly from year to year. In order to clarify the relative contributions by the synoptic-scale heat flux and wind stress forcing, it is instructive to look into the detailed evolution of the modeled upper-ocean thermal structures in 1997 and 1998. As seen in Fig. 10, the cooling effect is significantly greater in 1997 than in 1998. It is worth emphasizing that this interannual difference is not just a model result. In fact, this excessive cooling effect is responsible for the colder SSTs observed at the buoy site in summer of 1997 as compared to summer of 1998 (see Fig. 11a).

Figure 11b compares the SST changes between the climatological model run and three synoptic-scale runs for 1997 and 1998. The red curve shows the result when the synoptic-scale heat flux forcing alone is added to the climatological forcing, and the blue curve when the synoptic-scale wind stress forcing alone is added. The black curve is the same as that shown in Fig. 10 with both the synoptic-scale heat flux and wind stress forcing
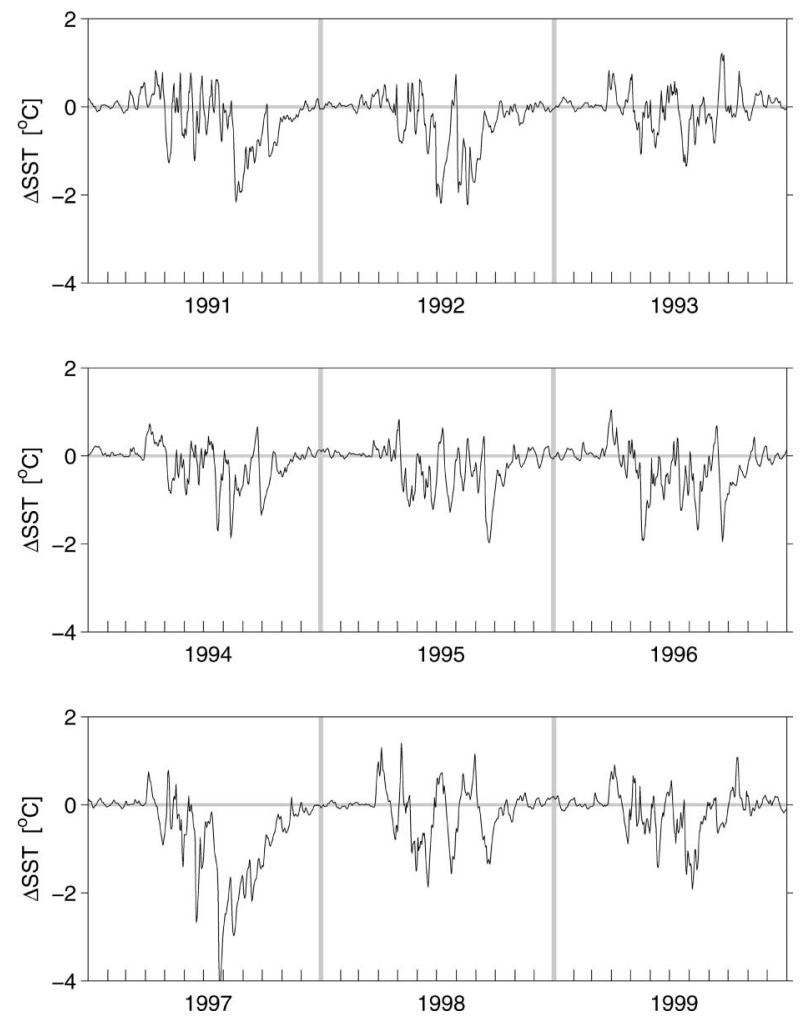

FIG. 10. Changes in sea surface temperature between the climatological model run and the model run with the synoptic-scale surface flux forcing added. Negative anomalies denote colder SSTs simulated in the synoptic-scale model run case.

included. To a large extent, the black curve is equal to the sum of the red and blue curves, implying the effect of the synoptic-scale heat flux and wind stress forcing upon the SST signals is more or less linear. From the red curve, it is interesting to note that the SST signals induced by the synoptic-scale heat flux forcing is largely oscillatory in nature; it reflects the direct impact of the heat flux forcing upon the SST signals [i.e., $\partial(\mathrm{SST}) / \partial t$ $\left.\propto Q_{\text {net }}\right]$.

The effect of the synoptic-scale wind stress forcing upon the SST signals is, on the other hand, more subtle. Cooling of SST due to the wind-induced entrainment occurs only when the wind stress forcing is intense enough to cause shear instability at the base of the mixed layer (Price et al. 1986). Plotting the increase in the mixed layer depth as a result of the bulk Richardson number instability (Fig. 11c) reveals that the cooling signals shown by the blue curve in Fig. 11b correspond well to the wind-induced deepening events of the mixed layer. Since the wind-induced entrainment works only to lower the SSTs, the magnitude of the overall cooling of SST depends on the cumulative effect of the synopticscale wind stress forcing. A year with more vigorous synoptic-scale wind stress forcing, such as in 1997 (see Fig. 4), will have colder SSTs in summer and autumn, whereas a year with weaker synoptic-scale wind stress 


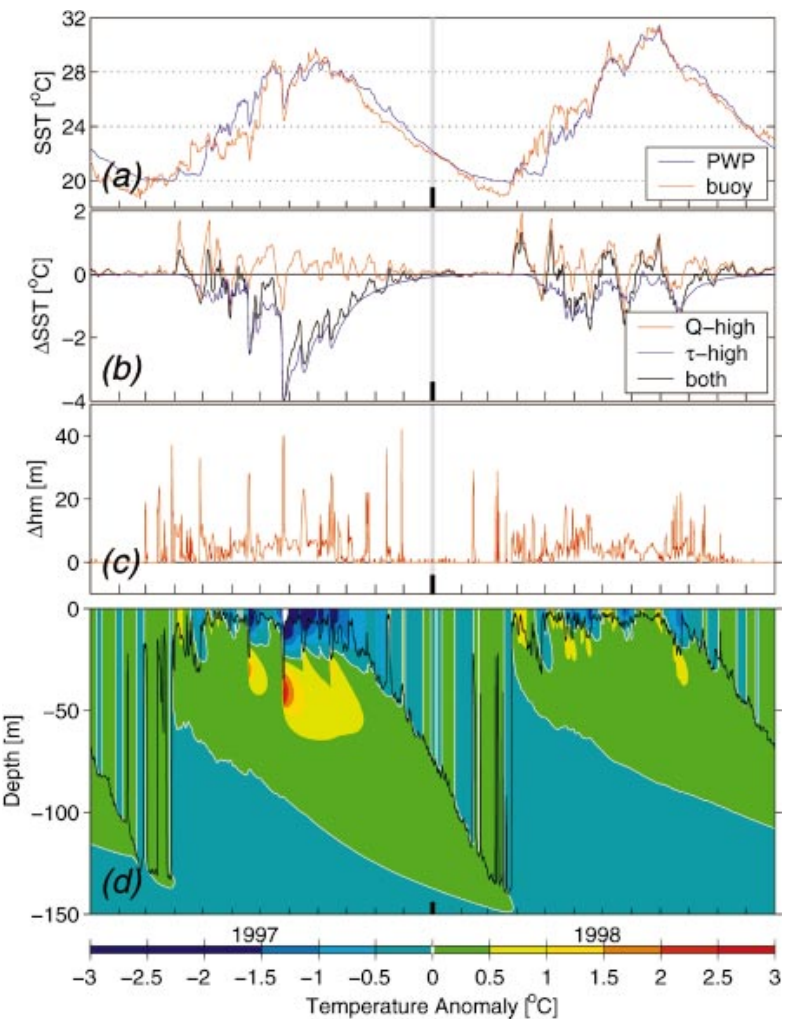

FIG. 11. (a) Time series of the observed SST (red) vs that from the synoptic-scale model run (blue). (b) SST differences between the climatological model run and three synoptic-scale runs. The red (blue) curve denotes the result when only the synoptic-scale heat flux (wind stress) forcing is considered. The black curve denotes the result when both forcings are considered. (c) Increase in mixed layer depth resulting from the bulk Richardson number mixing in the synopticscale model run. (d) Difference in temperature between the climatological run and the synoptic-scale run. The dark black line denotes the mixed layer depth in the synoptic-scale model run.

forcing, such as in 1998, will tend to have warmer SSTs in summer and autumn.

It is worth noting that subsurface layers tend to have temperature anomalies with the sign opposite to that of the SST anomalies. In 1997 when the synoptic-scale wind stress forcing is intense, for example, enhanced mixing near the base of the mixed layer causes excessive warm surface water to be subducted below the mixed layer (see Fig. 11d). This is in contrast to 1998, during which wind-induced mixing is weaker and the subsurface layer remains comparatively colder. Plotting the modeled temperature anomalies at the 100-m depth (Fig. 12) reveals that the synoptic-scale forcing lowers the water temperature over the period when the surface mixed layer depth is shallow (i.e., from April to October) as a result of enhanced entrainment in the previous winter. This cooling effect, however, changes interannually depending on the strengths of the synopticscale forcing: the colder subsurface anomalies of 1993 and 1994 correspond to the years when the synopticscale wind stress forcing is less intense and the SST

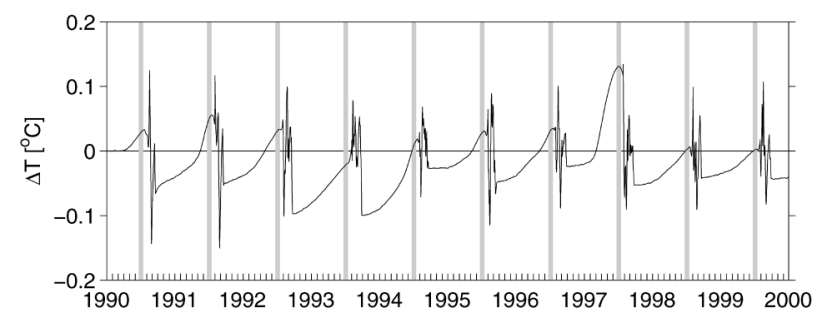

FIG. 12. Temperature difference $(\Delta T)$ between the climatological and synoptic-scale model runs at the 100-m depth. The full-depth time series of $\Delta T$ for 1997 and 1998 can be seen in Fig. 11d.

anomalies are less cold (see Fig. 10), whereas the warmest subsurface anomaly occurs in 1997 when the SST anomalies are the coldest and the synoptic-scale wind stress forcing is most active.

\section{c. High-frequency SST variability}

As the SST is a directly observed variable, it is of interest to compare the observed signals with those simulated in the synoptic-scale model run. While the dominant SST signal at the buoy site is seasonal (the peakto-peak seasonal SST modulation, as shown in Fig. 11a, is $\sim 9^{\circ} \mathrm{C}$ ), the observed SSTs also fluctuate significantly at higher frequencies because of synoptic-scale atmospheric forcing. Figure 13 compares the high-pass-fil-
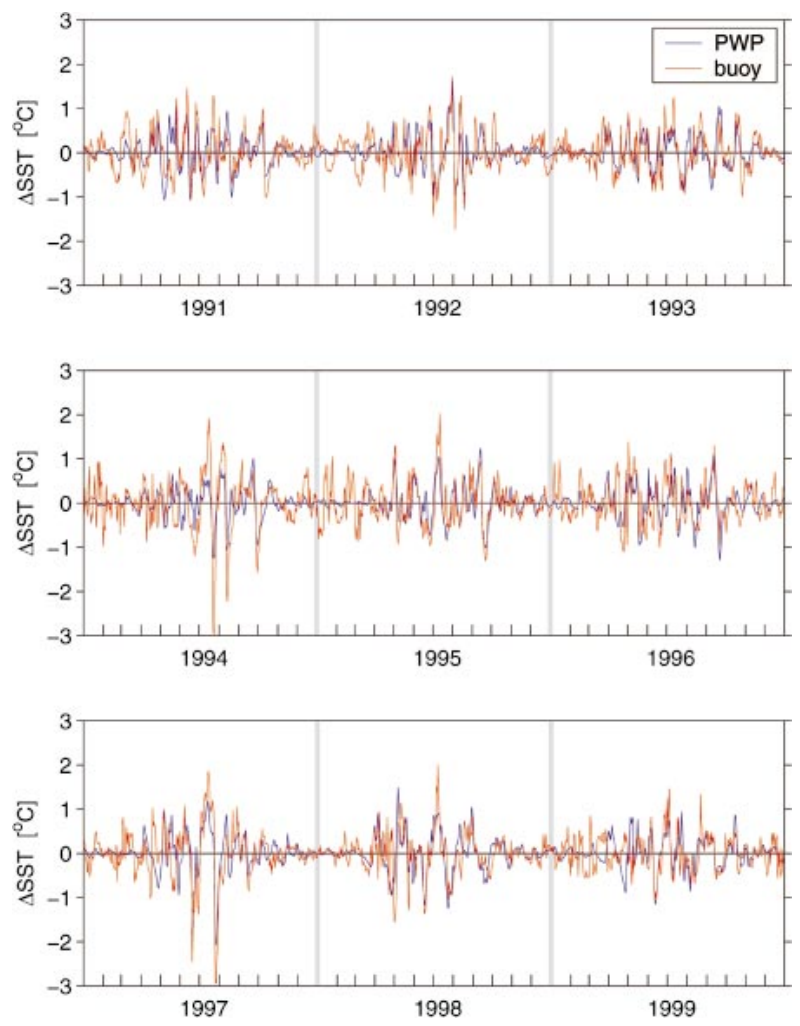

FIG. 13. Comparison between the high-pass-filtered SST time series of the buoy observations (red) and the synoptic-scale model run (blue). The high-pass filter has a cutoff period at 2 months. 

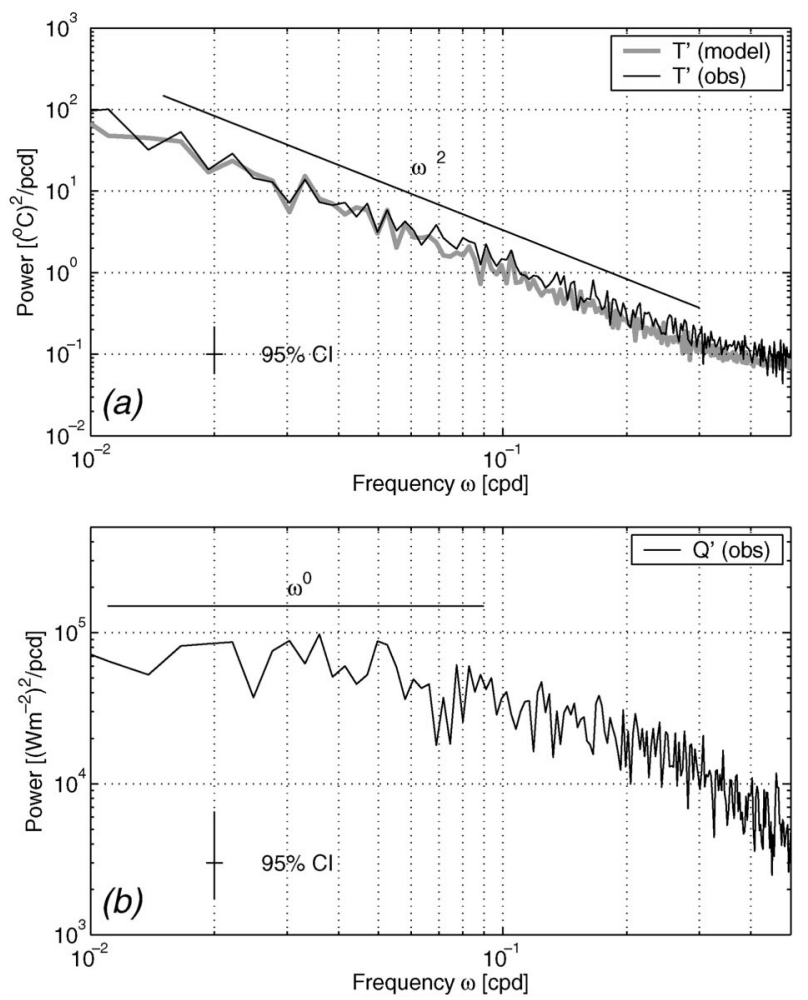

FIG. 14. (a) Frequency spectra of the SSTs from the buoy observations (thin black curve) and from the PWP model (thick gray curve). (b) Frequency spectrum of the net surface heat flux data from the buoy observations.

tered SST time series from the buoy measurements and the synoptic-scale model run (see Fig. 11a for the unfiltered time series in 1997 and 1998). Despite the simplicity of the PWP model physics, the model simulation is able to capture many of the synoptic-scale SST changes observed by the buoy. The two time series in Fig. 13 have a linear correlation coefficient of 0.59 ; with the decorrelation scale estimated at about 10 days, the correlation is significant at the $99 \%$ confidence level.

It is interesting to note that the power spectra for both the observed and modeled SST time series have a welldefined $\omega^{-2}$ dependency (Fig. 14a). That the frequency spectra of SST have a -2 slope was previously noted by Frankignoul and Hasselmann (1977). Using the concept of stochastic forcing, Frankignoul and Hasselmann showed that the $\omega^{-2}$ dependency for the observed SST signals could be adquately explained by the "white noise" surface heat flux forcing. A look at the observed surface net heat flux forcing for the present study (Fig. $14 \mathrm{~b})$ reveals that the frequency spectrum for $Q_{\text {net }}$ is indeed "white" in the frequency range of $1 / 100$ to $1 / 16$ days. For $\omega>1 / 16$ days, however, the power of the net heat flux forcing tends to decreases with the frequency. From the classic stochastic forcing model, this would lead to the slope of the SST spectrum being steeper than -2 , in contradiction to the observed $\omega^{-2}$ dependency.
One assumption adopted in Frankignoul and Hasselmann's (1977) model is that the surface mixed layer depth is constant. As indicated by the black curve in Fig. 11d, this clearly is not the case, as the mixed layer depth can modulate significantly in response to the synoptic-scale heat flux and wind stress forcing. Changes in the mixed layer depth alter the thickness over which the surface heat input/loss is being distributed. As such, in the high-frequency band where the mixed layer depth change is significant (see, e.g., Fig. 11), it is not surprising to find that the SST signals do not behave simply as an integrator of the net heat flux forcing. To understand the SST variability on the semimonthly or shorter time scales, we clearly need to take the dynamics of high-frequency mixed layer changes into account.

\section{Summary and discussion}

The western boundary current outflow region of the subtropical gyre is where the largest heat exchange takes place across the air-sea interface in the North Pacific Ocean. Using the surface meteorological data from a JMA buoy at $29^{\circ} \mathrm{N}, 135^{\circ} \mathrm{E}$, we carried out an in-depth analysis of the air-sea flux forcing in this region. The decade-long buoy observations not only allowed us to document surface heat and momentum fluxes over a broad range of frequencies, it also provided a unique reference site to evaluate the air-sea flux products from operational weather forecast assimilation and analysis models.

As is typical for midlatitude oceans, the surface heat fluxes at the buoy site have well-defined annual cycles, and the observed seasonal (summer - winter) amplitudes of the turbulent and radiative heat fluxes reach 220 and $170 \mathrm{~W} \mathrm{~m}^{-2}$, respectively. For the monthly turbulent heat flux climatology, a comparison with the NCEP reanalysis product revealed that the NCEP result has a bias of overestimating the flux amplitude. This bias is particularly large $\left(>60 \mathrm{~W} \mathrm{~m}^{-2}\right)$ in winter months where modeled turbulent heat flux values of individual synoptic-scale disturbances exceeded persistently those of the observations. Similar to the turbulent heat flux climatology, amplitudes of the monthly radiative heat fluxes in the NCEP product also have an overestimating bias. Examining the flux components indicated that much of this bias was due to the overestimation of incoming solar radiation at the sea surface. Because the turbulent and radiative heat fluxes contribute oppositely to the net heat flux across the sea surface, the bias for the monthly $Q_{\text {net }}$ climatology is smaller than the biases of the composing components.

On the subseasonal time scales, the surface wind and heat flux forcing at the buoy site is dominated by signals reflecting the synoptic-scale weather disturbances. For both the observed surface heat flux and wind stress time series, there exist no distinct spectral peaks. Rather, the large-amplitude heat flux forcing appears in the broad frequency band from $1 / 14$ to $1 / 3$ days, and the surface 
wind forcing has more energy in the higher-frequency band of $1 / 8-1 / 2$ days. While overestimating the heat flux amplitude of individual weather disturbances, we found that the NCEP product captured the timing and the relative strengths of the net heat flux forcing associated with the weather disturbances very well. The ratio of the synoptic-scale net heat flux forcing rms variability from the NCEP product to that from the buoy measurements is found to be 1.23. For the synoptic-scale surface wind stress forcing, we found that with the exception of underestimating amplitudes of a few extreme storm events (for which the wind stress magnitude exceeds $0.7 \mathrm{~N} \mathrm{~m}^{-2}$ ), the NCEP product compares very favorably with the observed wind stresses at the buoy.

Using the observed air-sea flux data from the buoy, we investigated next the impact of the synoptic-scale atmospheric forcing upon the upper-ocean thermal structures. By adopting the mixed layer model of Price et al. (1986), we assessed this impact by contrasting the model runs with and without the inclusion of the synoptic-scale air-sea flux forcing. The effect of the synoptic-scale flux forcing is most noticeable in the SST signals of the spring and summer seasons. During these seasons, the surface mixed layer is relatively shallow and the synoptic-scale heat flux forcing can significantly modify the SST signals. The SST anomalies thus generated have a typical amplitude of $\pm 1^{\circ} \mathrm{C}$. The springand summertime seasonally averaged SSTs are also affected by the synoptic-scale wind forcing. By generating shear instability at the base of the mixed layer, largeamplitude wind forcing can lower the SST through entrainment of colder water from beneath the mixed layer. The magnitude of the SST anomalies resulting from this process depends on the accumulation of large-amplitude wind events: the larger the accumulation, the colder the SST anomalies. This process is found to be the cause for the unseasonably cold SSTs observed at the buoy site in summer of 1997. Below the seasonal mixed layer, the synoptic-scale wind-induced temperature anomalies tend to have their sign opposite to that of the SST anomalies.

For SST signals with periods shorter than 100 days, we found that their frequency spectra from the observations and the PWP model have a well-defined $\omega^{-2}$ dependency. While this dependency is consistent with the "white" surface heat flux forcing in the frequency band of $1 / 100 \sim 1 / 16$ days, we found that in the higherfrequency band, short-term mixed layer depth changes caused by the synoptic-scale atmospheric forcing are likely to be important in determining the spectral shape of the SST signals.

Throughout this study, we have focused on the synoptic-scale air-sea flux forcing at a buoy site south of Japan. It is worth emphasizing that the results described in the present study are by no means specific to this particular site. A look at the NCEP net heat flux product reveals that the region with large-amplitude synopticscale heat flux forcing extends over the entire paths of

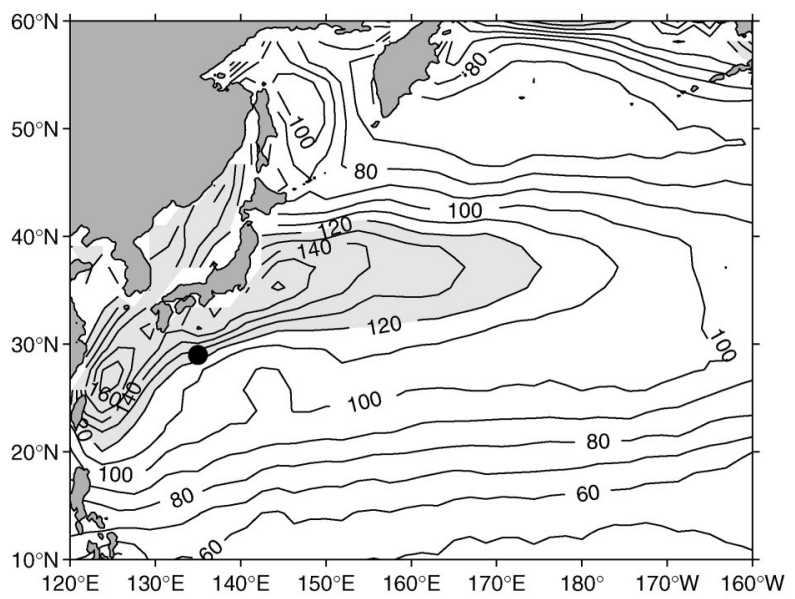

FIG. 15. Rms amplitude of the high-frequency [ $\omega>1 /(2$ months $)]$ net surface heat flux signals in the western North Pacific. Based on the daily NCEP reanalysis product. Units in $\mathrm{W} \mathrm{m}^{-2}$. Shaded areas denote the rms amplitude exceeding $120 \mathrm{~W} \mathrm{~m}^{-2}$, and the dot at $29^{\circ} \mathrm{N}$, $135^{\circ} \mathrm{E}$ denotes the location of the JMA buoy 21004.

the subtropical gyre western boundary current and its extension: the Kuroshio and the Kuroshio Extension (see Fig. 15). In fact, the synoptic-scale atmospheric forcing is more energetic in the downstream Kuroshio Extension region than at the JMA buoy site south of Japan. As the region southeast of Japan is where the subtropical mode water is preferentially formed (e.g., Hanawa and Talley 2001), studies of the mode water formation and transformation in the future clearly need to account for the roles played by the synoptic-scale air-sea forcing.

In assessing the impact of the synoptic-scale atmospheric forcing upon the upper ocean, we have limited our attention in this study to the one-dimensional thermodynamic effect. As the synoptic-scale surface forcing and the background oceanic mean state vary spatially, the forcing-induced upper-ocean thermal structure anomalies will necessarily alter the upper-ocean circulation because of the horizontally varying pressure gradient. Once the horizontal circulation field is modified, it can in turn influence the upper-ocean heat balance by horizontal heat advection and by lateral induction of the mixed layer and thermocline waters across the sloping mixed layer. Because this dynamic and thermodynamic interplay is likely to affect SSTs on the low-frequency time scales, future studies are required to clarify this interplay within a three-dimensional ocean model setting.

Acknowledgments. This study benefited from fruitful discussions with Ted Durland, Masanori Konda, Hisashi Nakamura, and Rob Scott. Detailed comments made by the anonymous reviewers helped to improve an early version of the manuscript. The in situ data of buoy 21004 were generously provided to us by the Japan Meteorological Agency, and the reanalysis product of 
surface wind stress and heat flux data were provided by the National Centers for Environmental Prediction. This study was supported by NSF Grant OCE-0220680 as part of the Collaborative Research: Kuroshio Extension System Study (KESS).

\section{REFERENCES}

Anderson, S. P., R. A. Weller, and R. B. Lukas, 1996: Surface buoyancy forcing and the mixed layer of the western Pacific warm pool: Observation and 1D model results. J. Climate, 9, 30563085.

Barnett, T. P., D. W. Pierce, R. Saravanan, N. Schneider, D. Dommenget, and M. Latif, 1999: Origins of the midlatitude Pacific decadal variability. Geophys. Res. Lett., 26, 1453-1456.

Berliand, M. E., and T. G. Berliand, 1952: Measurement of the effective radiation of the earth with varying cloud amounts (in Russian). Izv. Akad. Nauk SSSR, Ser. Geofiz., 1, 64-78.

Clark, N. E., L. Eber, R. M. Laurs, J. A. Renner, and J. F. T. Saur, 1974: Heat exchange between ocean and atmosphere in the eastern North Pacific for 1961-71. NOAA Tech. Rep. NMFS SSRF682, U.S. Department of Commerce, Washington, DC, 108 pp.

Conkright, M. E., R. A. Locarnini, H. E. Garcia, T. D. O'Brien, T. P. Boyer, C. Stephens, and J. I. Antonov, 2002: World Ocean Atlas 2001: Objective Analyses, Data Statistics, and Figures: CD-ROM Documentation. National Oceanographic Data Center, Internal Rep. 17, CD-ROM.

Deser, C., and M. L. Blackmon, 1995: On the relationship between tropical and North Pacific sea surface variations. J. Climate, 8, $1677-1680$.

Fairall, C. W., E. F. Bradley, D. P. Rogers, J. B. Edson, and G. S Young, 1996: Bulk parameterization of air-sea fluxes for Tropical Ocean Global Atmosphere Coupled-Ocean Atmosphere Response Experiment. J. Geophys. Res., 101, 3747-3764.

Frankignoul, C., and K. Hasselmann, 1977: Stochastic climate models, Part II: Application to sea-surface temperature anomalies and thermocline variability. Tellus, 29, 284-305.

Fung, I. Y., D. E. Harrison, and A. A. Lacis, 1984: On the variability of the net longwave radiation at the ocean surface. Rev. Geophys. Space Phys., 22, 177-193.

Gasper, P., 1988: Modeling the seasonal cycle of the upper ocean. $J$. Phys. Oceanogr., 18, 161-180.

Hanawa, K., and L. D. Talley, 2001: Mode waters. Ocean Circulation \& Climate: Observing and Modelling the Global Ocean, G. Siedler, J. Church, and J. Gould, Eds., Academic Press, 373-386.

Hsiung, J., 1985: Estimates of global oceanic meridional heat transport. J. Phys. Oceanogr., 15, 1405-1413.

JMA, 2001: Data report of oceanographic observations: 1965-1992 research vessel observation and 1978-2000 ocean data buoy observations. Climate and Marine Department, Japan Meteorological Agency Special Issue S1, Tokyo, Japan, CD-ROM.

Josey, S. A., 2001: A comparison of ECMWF, NCEP-NCAR, and SOC surface heat fluxes with moored buoy measurements in the subduction region of the northeast Atlantic. J. Climate, 14, $1780-1789$.

- E. C. Kent, and P. K. Taylor, 1998: The Southampton Oceanography Center (SOC) Ocean-Atmosphere Heat, Momentum and Freshwater Flux Atlas. Southampton Oceanography Center Rep. 6, $30 \mathrm{pp}$.

Kelly, K. A., 2004: The relationship between oceanic heat transport and surface fluxes in the western North Pacific: 1970-2000. J. Climate, 17, 573-588.

Kistler, R., and Coauthors, 2001: The NCEP-NCAR 50-year reanalysis: Monthly means CD-ROM and documentation. Bull. Amer. Meteor. Soc., 82, 247-267.

Kizu, S., 1998: Systematic errors in estimation of insolation by empirical formulas. J. Oceanogr., 54, 165-177.

Kurasawa, Y., K. Hanawa, and Y. Toba, 1983: Heat balance of the surface layer of the sea at Ocean Weather Station T. J. Oceanogr. Soc. Japan, 39, 192-201.

Large, W. G., 1996: An observational and numerical investigation of the climatological heat and salt balances at OWS Papa. J. Climate, 9, 1856-1876.

, and G. B. Crawford, 1995: Observations and simulations of upper-ocean response to wind events during the ocean storms experiment. J. Phys. Oceanogr., 25, 2831-2852.

Latif, M., and T. P. Barnett, 1996: Decadal climate variability over the North Pacific and North America: Dynamics and predictability. J. Climate, 9, 2407-2423.

Martin, P. J., 1985: Simulation of the ocean mixed layer at OWS November and Papa with several models. J. Geophys. Res., 90, 903-916.

Miller, A. J., D. R. Cayan, T. P. Barnett, N. E. Graham, and J. M. Oberhuber, 1994: Interdecadal variability of the Pacific Ocean: Model response to observed heat flux and wind stress anomalies. Climate Dyn., 9, 287-302.

Moyer, K. A., and R. A. Weller, 1997: Observations of surface forcing from the subduction experiment: A comparison with global model products and climatological datasets. J. Climate, 10, 27252742.

Nakamura, H., G. Lin, and T. Yamagata, 1997: Decadal climate variability in the North Pacific during the recent decades. Bull. Amer. Meteor. Soc., 78, 2215-2225.

Niiler, P. P., N. A. Maximenko, and J. C. McWilliams, 2003: Dynamically balanced absolute sea level of the global ocean derived from near-surface velocity observations. Geophys. Res. Lett., 30, 2164, doi:10.1029/2003GRL018628.

Paulson, C. A., and J. J. Simpson, 1977: Irradiative measurements in the upper ocean. J. Phys. Oceanogr., 7, 952-956.

Payne, R. E., 1972: Albedo of the sea surface. J. Atmos. Sci., 29, 959-970.

Peng, S., W. A. Robinson, and M. P. Hoerling, 1997: The modeled atmospheric response to midlatitude SST anomalies and its dependence on background circulation states. J. Climate, 10, 971987.

Plueddemann, A. J., R. A. Weller, M. Stramska, T. D. Dickey, and J. Marra, 1995: Vertical structure of the upper ocean during the Marine Light-Mixed Layers experiment. J. Geophys. Res., 100, $6605-6619$.

Price, J. F., R. A. Weller, and R. Pinkel, 1986: Observations and models of the upper ocean response to diurnal heating, cooling, and wind mixing. J. Geophys. Res., 91, 8411-8427.

Qiu, B., 2000: Interannual variability of the Kuroshio Extension and its impact on the wintertime SST field. J. Phys. Oceanogr., 30, $1486-1502$.

_, 2002: Large-scale variability in the midlatitude subtropical and subpolar North Pacific Ocean: Observations and causes. J. Phys. Oceanogr., 32, 353-375.

, and R. X. Huang, 1995: Ventilation of the North Atlantic and North Pacific: Subduction versus obduction. J. Phys. Oceanogr., 25, 2374-2390

Reed, R., 1977: On estimating insolation over the ocean. J. Phys. Oceanogr., 7, 482-485.

Schudlich, R. R., and J. F. Price, 1992: Diurnal cycles of current, temperature, and turbulent dissipation in a model of the equatorial upper ocean. J. Geophys. Res., 97, 5409-5422.

Smith, S. R., D. M. Legler, and K. V. Verzone, 2001: Quantifying uncertainties in NCEP reanalyses using high-quality research vessel observations. J. Climate, 14, 4062-4072.

Talley, L. D., 1984: Meridional heat transport in the Pacific Ocean. J. Phys. Oceanogr., 14, 231-241.

Trenberth, K. E., W. G. Large, and J. G. Olson, 1990: The mean annual cycle in the global ocean wind stress. J. Phys. Oceanogr., 20, 1742-1760.

Vivier, F., K. A. Kelly, and L. Thompson, 2002: Heat budget in the Kuroshio Extension region: 1993-99. J. Phys. Oceanogr., 32, $3436-3454$.

Weller, R. A., M. F. Baumgartner, S. A. Josey, A. S. Fischer, and J. C. Kindle, 1998: Atmospheric forcing in the Arabian Sea during 1994-1995: Observations and comparisons with climatology and models. Deep-Sea Res., 45, 1961-1999. 